\title{
Trends in hospital admissions, re-admissions, and in-hospital mortality among HIV-infected patients between 1993 and 2013: impact of hepatitis C co-infection
}

\author{
Tendencia de las hospitalizaciones, reingresos y mortalidad intrahospitalaria en \\ los pacientes infectados por VIH entre 1993-2013: impacto de la coinfección por \\ el virus de la hepatitis $C$
}

\author{
Héctor Meijide $^{\mathrm{a}, \mathrm{b}}$, Álvaro Mena ${ }^{\mathrm{a}}$, Iria Rodríguez-Osorio ${ }^{\mathrm{a}}$, Sonia Pértega ${ }^{\mathrm{c}}$, Ángeles \\ Castro-Iglesias ${ }^{\mathrm{a}}$, Guillermo Rodríguez-Martínez ${ }^{\mathrm{d}}$, José Pedreira ${ }^{\mathrm{a}}$, Eva Poveda ${ }^{\mathrm{a}}$ \\ ${ }^{a}$ Grupo de Virología Clínica, Instituto de Investigación Biomédica de A Coruña (INIBIC)-Complexo \\ Hospitalario Universitario de A Coruña (CHUAC), Sergas, Universidade da Coruña (UDC), Spain \\ ${ }^{b}$ Servicio de Medicina Interna, Hospital Quiron, A Coruña, Spain \\ ${ }^{c}$ Unidad de Epidemiología Clínica y Bioestadística, Instituto de Investigación Biomédica de A Coruña \\ (INIBIC)-Complexo Hospitalario Universitario de A Coruña (CHUAC), Sergas, Universidade da Coruña \\ (UDC), Spain \\ ${ }^{d}$ Unidad de Admisión y Documentación Clínica, Complexo Hospitalario Universitario de A Coruña \\ (CHUAC), Sergas, A Coruña, Spain
}

\begin{abstract}
Background. New patterns in epidemiological characteristics of people living with HIV infection (PLWH) and the introduction of Highly Active Antiretroviral Therapy (HAART) have changed the profile of hospital admissions in this population. The aim of this study was to evaluate trends in hospital admissions, readmissions, and mortality rates in HIV patients and to analyze the role of HCV co-infection.

Methods. A retrospective cohort study conducted on all hospital admissions of HIV patients between 1993 and 2013. The study time was divided in two periods (1993-2002 and 2003-2013) to be compared by conducting a comparative cross-sectional analysis.

Results. A total of 22,901 patient-years were included in the analysis, with 6917 hospital admissions, corresponding to 1937 subjects (75\% male, mean age $36 \pm 11$ years, 37\% HIV/HCV co-infected patients). The median length of hospital stay was 8 days (5-16), and the 30-day hospital re-admission rate was $20.1 \%$. A significant decrease in hospital admissions related with infectious and psychiatric diseases was observed in the last period (2003-2013), but there was an increase in those related with malignancies, cardiovascular, gastrointestinal, and chronic respiratory diseases. In-hospital mortality remained high $(6.8 \%$ in the first period vs. $6.3 \%$ in the second one), with a progressive increase of non-AIDS-defining illness deaths (37.9\% vs. $68.3 \%, P<.001)$. The admission rate significantly dropped after 1996 (4.9\% yearly), but it was less pronounced in $\mathrm{HCV}$ co-infected patients (1.7\% yearly).

Conclusions. Hospital admissions due to infectious and psychiatric disorders have decreased, with a significant increase in non-AIDS-defining malignancies, cardiovascular, and chronic respiratory diseases. Inhospital mortality is currently still high, but mainly because of non-AIDS-defining illnesses. HCV coinfection increased the hospital stay and re-admissions during the study period.
\end{abstract}




\section{Resumen}

Introducción. Los cambios en las características epidemiológicas de los pacientes con infección por el VIH, y la introducción del tratamiento antirretroviral de alta eficacia, han modificado el perfil de las hospitalizaciones en esta población. El objetivo del estudio fue evaluar las tendencias en hospitalización, reingreso y mortalidad en pacientes VIH, y analizar el papel de la coinfección por el VHC.

Métodos. Estudio de cohortes retrospectivo, que incluyó todas las hospitalizaciones de pacientes VIH entre 1993-2013. El estudio fue dividido en 2 periodos (1993-2002 y 2003-2013) para ser comparados mediante un análisis transversal.

Resultados. Se analizaron 22.901 pacientes/años, que presentaron 6.917 hospitalizaciones que correspondieron a 1.937 pacientes (75\% varones, edad media $36 \pm 11$ años, $37 \%$ coinfectados VIH/VHC). La mediana de estancia hospitalaria fue de 8 días (5-16), y la tasa de reingreso a los 30 días del 20,1\%. Se observó un descenso significativo en el segundo periodo (2003-2013) de las hospitalizaciones motivadas por enfermedades infecciosas y trastornos psiquiátricos, y un incremento de aquellas relacionadas con neoplasias, enfermedad cardiovascular, gastrointestinal y enfermedades respiratorias crónicas. La mortalidad intrahospitalaria permanece elevada (6,8\% en el primer periodo vs. $6,3 \%$ en el segundo), con un aumento progresivo de las muertes por enfermedades no definitorias de sida (37,9 vs. 68,3\%; p < 0,001). La tasa de hospitalización disminuyó de manera significativa después de 1996 (4,9\% anual), pero este descenso fue menos acusado en los pacientes coinfectados VIH/VHC (1,7\% anual).

Conclusiones. Las hospitalizaciones motivadas por enfermedades infecciosas y trastornos psiquiátricos han descendido; por el contrario, se observó un aumento significativo de aquellas relacionadas con neoplasias no definitorias de sida, enfermedad cardiovascular y enfermedades respiratorias crónicas. La mortalidad intrahospitalaria permanece a día de hoy elevada, pero a expensas fundamentalmente de enfermedades no definitorias de sida. La coinfección VIH/VHC incrementó los días de hospitalización y los reingresos durante el periodo de estudio.

Keywords

HIV/AIDS; HCV co-infection; Hospital admission; Re-admission

Palabras clave

VIH/sida; Coinfección VIH/VHC; Hospitalización; Reingreso

\section{Background}

Since the introduction of Highly Active Antiretroviral Therapy (HAART) in 1996, the profile of people living with HIV infection (PLWH) has changed significantly; with an appreciable decline of mortality related to AIDS-defining diseases and an improvement in life expectancy. However, the incidence of other comorbidities, mainly cardiovascular diseases and non-AIDS tumors has increased, due to the longer life expectancy, aging and persistent inflammation related to the HIV-infection, even in a context of long-term suppression of viremia. $1 ; 2 ; 3 ; 4 ; 5$

From a public health perspective, it is important to understand trends and characteristics of hospitalizations, re-admissions and mortality rates among PLWH. However, there are few available data among too heterogeneous study populations in different socioeconomic contexts and Health Care systems. In the general population, 30-days readmission rates are increasingly becoming a benchmark for hospital quality of care and costs, also for PLWH. ${ }^{6}$

The causes of hospitalizations have been changing in the HAART era. AIDS defining illnesses are less represented nowadays, but patients are older with more comorbidities. Therefore, the reasons for hospitalizations incidence, mortality and readmission rates might be changing. ${ }^{6 ; 7 ; 8}$ $9 ; 10$

Chronic hepatitis $\mathrm{C}$ virus (HCV) coinfection is common in PLWH (30-50\% according to different series). ${ }^{11}$ It is estimated that at least $30 \%$ of patients with HCV develop cirrhosis and around $1-4 \%$ of these will develop hepatocellular carcinoma. The risk of progression of liver 
disease is 2-6 times higher in HIV/HCV coinfected than in HCV mono-infected patients, which involves a high-related morbidity and mortality. ${ }^{12}$ 13; 14; $15 ; 16$ However, the risk of hepatic decompensation and progression of liver fibrosis is drastically reduced with treatment and cure of HCV infection. ${ }^{17 ; 18}$

In this context, the aim of this study was to analyze trends in hospitalization, re-admission and mortality rates in PLWH followed in a reference hospital in Northwest Spain in the last 20 years. Moreover, the impact of $\mathrm{HCV}$ coinfection in the dynamic of all these parameters was also evaluated.

\section{Methods}

The Complexo Hospitalario Universitario de A Coruña (CHUAC) is a 1422-bed, full service, $24 \mathrm{~h}$ ICU availability, tertiary acute university care hospital, serving in the Northwest of Spain. The influence population in 2013 was 547,776 citizens, and that year reported 40,869 admissions (21\% scheduled). The HIV and Hepatitis Viral Unit offers outpatient and inpatient medical care to all PLWH in this reference area, attending more than 1400 PLWH by HIV-trained doctors. PLWH are not attended in other hospitals in this area.

\section{Data collection}

All hospital admissions of HIV-infected patients at CHUAC between 1993 and 2013 were obtained through the Hospital-coding Department. Hospitalization reasons were collected following the International Classification of Diseases, Ninth Revision (ICD-9). Several steps were taken in assigning each hospitalization to a single diagnostic category. To determine the reliably ICD-9 code the first listed referring to neither HIV (042, V08, 795.71, V01.79) nor chronic hepatitis C (070.44, 070.54, 070.70, 070.71) nor oral candidiasis (120.0) was defined as the primary code for hospitalization. These codes represent comorbidities that are not, by themselves, sufficient to justify hospitalization. Recurrent bacterial pneumonia was defined as a bacterial pneumonia admission occurring within $>30$ but $<365$ days of a previous such admission. Hospitalizations whose first ICD-9 code was chemotherapeutic treatment were assigned to the first code based on the type of cancer. Clinical Classification Software (CCS), developed by the Agency for Healthcare Research and Quality ${ }^{19}$ was used to assign primary ICD-9 code into one of 18 first-level categories. Finally, using a method similar to one it has previously employed, ${ }^{7} \mathrm{CCS}$ classification was modified and categories were pooled together at major syndromes for further analysis.

Epidemiological and clinical data related to hospitalizations and mortality were recorded. $\mathrm{HIV} / \mathrm{HCV}$ coinfection was considered if RNA-HCV viral load was detectable. Mean length of hospital stay was evaluated by subtracting the date of discharge - the date of admission and adding 1. For patients that were discharged the day of admission, it was considered 1. Re-admission was defined as hospitalization occurred before 30 days after discharge. Years of active outpatient care were defined by having at least one HIV clinician visit and one measured CD4 cell count. Scheduled admissions were considered if the patient were not in the Emergency Department prior to hospitalization. Death due to an AIDS-defining illness was defined as death attributable to one of the Centers for Disease Control Prevention (CDC) category C diseases. Death due to non AIDSdefining illness was classified according to CoDe protocol ("Coding of Death in HIV", in www.cphiv.dk/CoDe).

The study is in accordance with the community standards and approved by the ethics committee. The study's protocol was reviewed and approved by the Medical Ethics Committee of the University Hospital of Galicia. All clinical data were anonymous and de-identified prior to analyze, the identification numbers of the patients were recorded blindly. 


\section{Statistical analyses}

Hospitalization rate was evaluated as number of hospitalizations per 100 patients. For the denominator, the number of patients in care each year in the HIV clinic, was used; it was collected from medical records and electronic database of patients in follow up. The study was divided in two periods of time (1993-2002 and 2003-2013) to be compared with a comparative crosssectional analysis.

Quantitative data were reported using means \pm standard deviations (SD) or median (range), as indicated. For qualitative variables, absolute numbers and percentages were computed. The comparison of quantitative parameters was carried out using Student's $t$ test. The association of qualitative variables was carried out using Chi-squared statistic; the relative risk (RR) was calculated. A two-sided type I error of $5 \%$ was considered statistically significant.

A time-trend joinpoint regression analysis was performed. This technique provides the estimated annual percent change (APC) and allows detecting points in time at which significant changes in the trends occur. For each APC estimate, 95\% confidence interval was also calculated. Statistical analysis was performed using SPSS for Windows (version 19.0, SPSS Inc., Chicago, IL).

\section{Results}

\section{Demographic characteristics and hospitalization parameters}

A total of 2498 PLWH were followed during the period study, contributing to 22,901 patientyears (PY). In the study period 6917 hospital admissions were recorded, corresponding to 1937 subjects. Of them, 75.0\% were male, mean age (at first hospitalization) was $36.4 \pm 10.6$ years, and $37.2 \%$ were HIV/HCV coinfected. Among those PLWH hospitalized, $789(40.7 \%)$ have one admission; the median number of admission was 2 (IQR: 1-4). The hospitalization rate showed a reduction from 30.7/100 patients (CI95\%: 27.7-33.8) in 1993 to $19.9 / 100$ patients (17.7-22.2) in $2013(P<.001)$; Fig. 1 shows the hospitalization and mortality each year and the number of patients on follow-up.

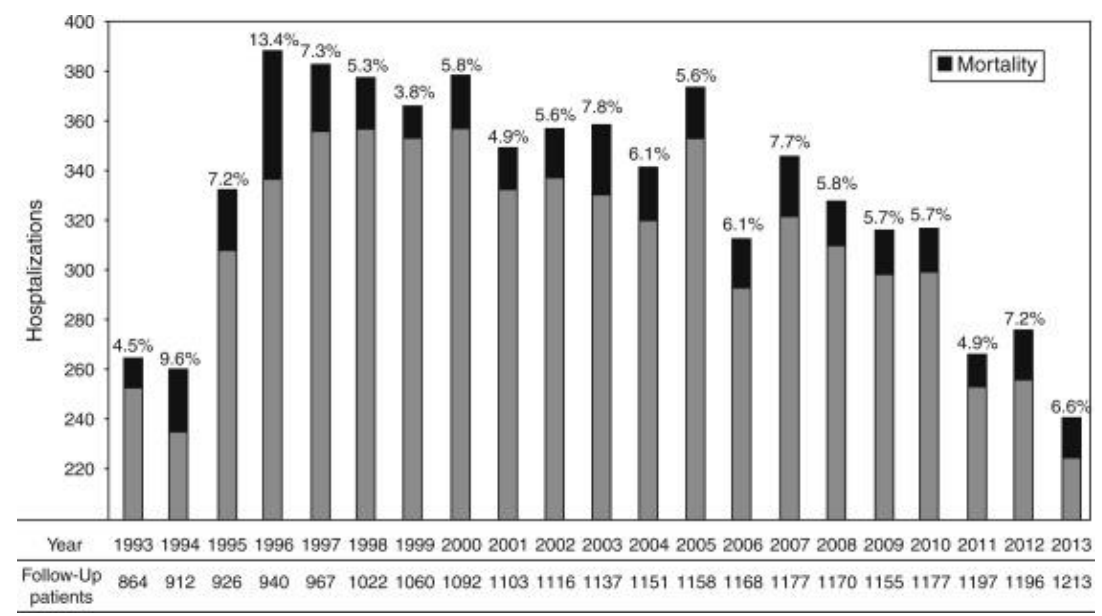

Fig. 1. Hospitalization in PLWH between 1993 and 2013; black area indicates mortality (\%). Patients on follow-up each year. 
In the comparative analysis between both periods (1993-2002 vs. 2003-2013), differences in hospitalization reasons were recognized among periods (Table 1). The main 5 reasons for hospitalization were: pneumonia $(10.5 \%)$, chronic pulmonary disease/respiratory failure $(8.3 \%)$, tuberculosis (7.4\%), hepatic decompensation (6.3\%) and psychiatric disorder/drug-abuse (5.3\%). Overall, 23.1\% of the total of 6917 hospitalizations was AIDS-defining illnesses, with differences between first $(28.0 \%)$ and second period $(16.2 \%), P<.001$.

Table 1. Baseline characteristics of 6917 hospital admissions between periods (1993-2002 and 2003-2013).

\begin{tabular}{|c|c|c|c|}
\hline & $1993-2002(N=3463)$ & $2003-2013(N=3454)$ & Relative change (\%) (CI 95\%) \\
\hline Scheduled admissions (\%) & 42.1 & 26.8 & $-36.3(-40.5 ;-31.9)$ \\
\hline Length of stay (median, IQR) & $9.0(5.0-16.0)$ & $8.0(4.0-15.0)$ & $-9.9(-18.7 ; 2.8)$ \\
\hline Re-admission (\%) & 19.8 & 20.4 & $3.0(-9.2 ; 13.2)$ \\
\hline Mortality (\%) & 6.8 & 6.3 & $-7.0(-22.1 ; 18.1)$ \\
\hline \multicolumn{4}{|l|}{ Hospitalization reasons (\%) } \\
\hline Infectious diseases & 49.1 & 35.3 & $-28.1(-32.0 ;-23.9)$ \\
\hline Aids-defining infections & 52.3 & 36.5 & $-30.2(-36.0 ;-23.9)$ \\
\hline Psyquiatric illness & 9.1 & 5.2 & $-42.7(-52.0 ;-31.6)$ \\
\hline Malignancies & 3.6 & 7.8 & $115.8(75.4 ; 165.3)$ \\
\hline Aids-defining tumors & 65.2 & 42.6 & $-34.8(-46.0 ;-21.2)$ \\
\hline Cardiac diseases & 1.2 & 3.7 & $205.6(116.3 ; 331.6)$ \\
\hline Digestive system diseases & 9.2 & 16.1 & 74.8 (53.6; 98.9) \\
\hline Hepatic decompensations & 4.2 & 8.5 & $103.3(67.6 ; 146.6)$ \\
\hline Chronic respiratory diseases & 5.6 & 11.0 & $96.4(66.3 ; 131.9)$ \\
\hline \multicolumn{4}{|l|}{ Hospitalization units (\%) } \\
\hline Internal medicine/infectious diseases & 85.0 & 70.8 & $-16.7(-18.9 ;-14.5)$ \\
\hline Surgical units & 5.0 & 10.4 & $108.0(74.6 ; 147.9)$ \\
\hline Onco-hematology & 2.0 & 4.3 & $116.5(63.4 ; 186.9)$ \\
\hline Gynecology/obstetrics & 2.7 & 4.3 & $58.9(23.3 ; 104.9)$ \\
\hline Pediatrics & 1.5 & 0.3 & $-80.7(-90.2 ;-62.1)$ \\
\hline Intensive care unit & 2.0 & 6.0 & $200.8(130.0 ; 293.4)$ \\
\hline Cause of in-hospital death $(\%)$ & $235 / 453$ & $218 / 453$ & \\
\hline AIDS related illness: & 62.1 & 31.7 & $-49.0(-59.1 ;-36.6)$ \\
\hline Aids related encephalopaty & 17.0 & 5.0 & $-70.4(-84.4 ;-43.7)$ \\
\hline MAI-MTB infection ${ }^{\mathrm{b}}$ & 15.3 & 6.0 & $-61.1(-78.8 ;-28.6)$ \\
\hline Pneumocistis jirovecci pneumonia & 11.5 & 6.0 & $-48.1(-72.5 ;-2.0)$ \\
\hline Aids related malignancy & 8.5 & 11.0 & $29.4(-26.4 ; 127.4)$ \\
\hline Disseminated candidiasis & 3.8 & 0.5 & $-88.0(-98.5 ;-6.2)$ \\
\hline Recurrent bacterial pneumoniae & 3.4 & 1.8 & $-46.1(-83.5 ; 76.5)$ \\
\hline Wasting syndrome & 2.6 & 1.4 & $46.1(-86.3 ; 112.9)$ \\
\hline Non-AIDS related illness: & 37.9 & 68.3 & $80.5(49.7 ; 117.6)$ \\
\hline$(02.1)$ Bacterial infection $^{c}$ & 10.2 & 17.0 & $66.2(2.9 ; 168.4)$ \\
\hline (02.1.1) Bacterial infection with sepsis & 6.8 & 12.8 & $88.6(5.0 ; 238.9)$ \\
\hline (03.1.1) HCV with cirrhosis & 5.1 & 11.0 & $115.6(10.5 ; 320.5)$ \\
\hline (04) Malignancy ${ }^{\mathrm{d}}$ & 2.6 & 9.6 & $277.3(55.2 ; 817.3)$ \\
\hline (16)Violent death/(19)substance abuse & 3.4 & 1.4 & $-59.6(-89.1 ; 50.4)$ \\
\hline (9) Stroke and (23) other CNS disease & 3.4 & 5.5 & $61.7(-32.6 ; 288.0)$ \\
\hline (13) Chronic obstructive lung disease $e^{e}$ & 2.6 & 7.8 & $205.4(22.7 ; 660.5)$ \\
\hline (08) MI and other heart disease & 0.4 & 1.4 & $223.4(-66.1 ; 2985.6)$ \\
\hline
\end{tabular}


Main causes of in-hospital mortality.

Statistically significant results $(P<.05)$ are shown in bold.

${ }^{a}$ Including progressive multifocal leukoencephalopathy, cryptococcal meningitis and cerebral toxoplasmosis.

${ }^{\mathrm{b}}$ Micobacterium Avium Intracellulare and Micobacterium Tuberculosis.

${ }^{\mathrm{c}}$ Only due to pneumonia.

${ }^{\mathrm{d}}$ Including hepatocarcinoma.

${ }^{\mathrm{e}}$ Including other chronic respiratory diseases.

\section{Re-admissions and mortality rates by clinical units}

Overall, $5759(83.3 \%)$ were considered primary hospitalizations, 998 (14.4\%) were first readmissions and $160(2.3 \%)$ were subsequent re-admissions in a chain. The median length of hospital stay was 8.0 days (5.0-16.0).

The re-admission rate was $20.1 \%$ (CI95\%: 19.1-21.2) without differences by gender $(20.3 \%$ in men vs. $19.7 \%$ in women, $P=.21)$. Mean age of patients in hospitalizations without a readmission (37.4 \pm 10.4 ) was similar than those re-admitted (37.9 \pm 10.9 years). A higher rate of readmissions was observed for some services such as Onco-Hematology (68.5\%), GynecologyObstetrics (24.2\%), Internal Medicine-Infectious Diseases (20.0\%) or Pediatric Unit (16.3\%). Those with lower rate were: surgery units $(13.2 \%)$ or Psychiatry Unit (8.2\%). Main reasons for hospital admission have different re-admission rates: tumoral diseases $33.8 \%$, hepatic decompensations $23.5 \%$, chronic pulmonary diseases $20.8 \%$, infectious diseases $18.9 \%$, cardiovascular diseases $14.9 \%$, and psychiatric disorders $12.8 \%$.

Between 1993-2013, 453 in-hospital deaths were identified, with an overall inpatient mortality rate of $6.5 \%$ (CI95\%: 6.0-7.1). Globally, the mortality of hospitalizations for males was higher than for women $(7.4 \%$ vs. $4.4 \%$, RR: 1.7 [1.3-2.1], $P<.001)$. Mean age of patients who died during the hospitalizations was $40.1 \pm 11.3$ years, significantly higher $(P<.001)$ than that of those who did not die $(37.3 \pm 10.4$ years). Mortality of primary hospitalizations was $5.7 \%$ vs. $11.0 \%$ among re-admissions (RR 1.93 [1.59-2.35], $P<.001$ ). AIDS-defining illnesses hospitalizations presented a mortality of $13.4 \%$, while in non AIDS-defining diseases was 4.5\% (RR: 3.0 [2.5-3.6], $P<.001)$.

There were differences in mortality rate by Units $(P=.005)$ : Onco-Hematology $(12.4 \%)$, Internal Medicine-Infectious Diseases (6.7\%), Surgery (3.6\%) and Pediatric (3.5\%). No patient's death in Gynecology-Obstetrics or Psychiatry Unit. There were 24 hospitalizations admitted in ICU directly from the Emergency Department, 21 of them $(87.5 \%)$, died during the ICU stay. Hospitalizations that were admitted in ICU (whenever during the hospitalization) had higher mortality rate $(35.5 \%)$ than those without ICU care $(5.3 \%)$ (RR 6.6 [5.5-8.0], $P<.001)$. The main causes of in-patient death and the change between both periods are detailed in Table 1.

\section{HIV/HCV coinfection}

A total of $716 \mathrm{HIV} / \mathrm{HCV}$ coinfected patients were hospitalized at least once during the study period, giving a total of 3525 hospitalizations (1408 between 1993-2002 and 2117 between 20032013). Fig. 2 depicts the changes in incidence during the follow up. In the joinpoint regression analysis, two different trends were observed. Hospitalizations rate increased between 1993 and 1996 in all cohort $(\mathrm{APC}=11.8 \%)$. Between 1997 and 2013, hospitalizations rate decreased much more in HIV mono-infected (APC $=-4.9 \%$ ) than in $\mathrm{HIV} / \mathrm{HCV}$ coinfected $(\mathrm{APC}=-1.7 \%)$, $P<.001$. 


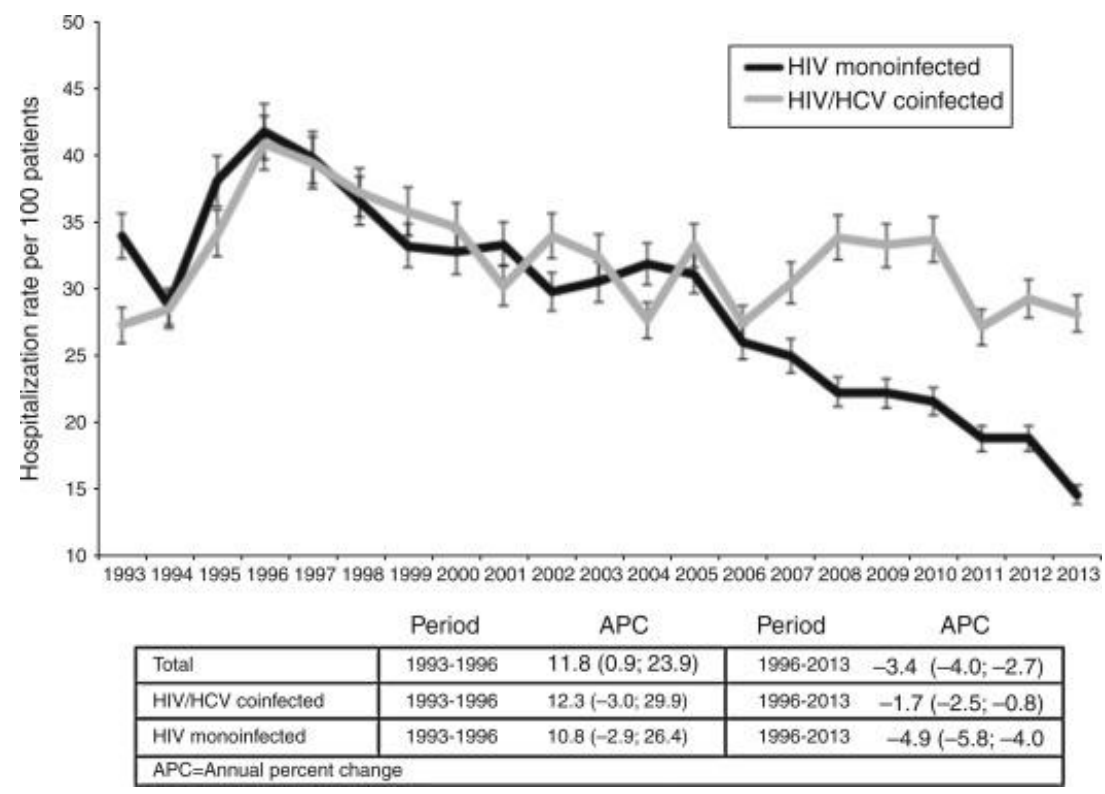

Fig. 2. Hospitalization rate in HIV/HCV coinfected and HIV monoinfected patients. Joinpoint regression analysis: trends in hospitalizations in HIV/HCV coinfected and HIV monoinfected patients. Estimated Annual percent change (bold if statistically significant, $P<.001$ in all cases). In comparison between HIV/HCV coinfected and HIV monoinfected patients, $P=.65$ in the first period (1993-1996) and $P<.001$ in the second (1996-2013).

Overall, the mean length of stay in HCV coinfected patients was similar than in mono-infected (median: 10.1 days [6.3-15.9] vs. 11.0 [6.0-19.5], $P=.24$ ); but coinfected had more hospitalizations per patient (median: $3.0[1.0-6.0]$ vs. $2.0[1.0-3.0], P<.001$ ) and higher readmission rates $(21.5 \%$ vs. $19.1 \%$, RR: 1.1 [1.0-1.2], $P<.001)$. The sum of total days of hospitalization per patient during the follow-up was higher among HIV/HCV coinfected than in HIV mono-infected (median: 36.0 days [14.0-77.5] vs. 23.0 days [9.0-51.0], respectively; $P<.001)$.

The main causes of hospitalization in coinfected patients, comparatively with HIVmonoinfected, are illustrated in Fig. 3. A decrease of infectious diseases and psychiatric disorders was evidenced. On the other hand, an important increase in hospitalizations due to hepatic decompensations was found (from 5.8\% to $11.5 \%$, RR: 2.0 [CI95\%: 1.5-2.6], $P<.001$ ). 

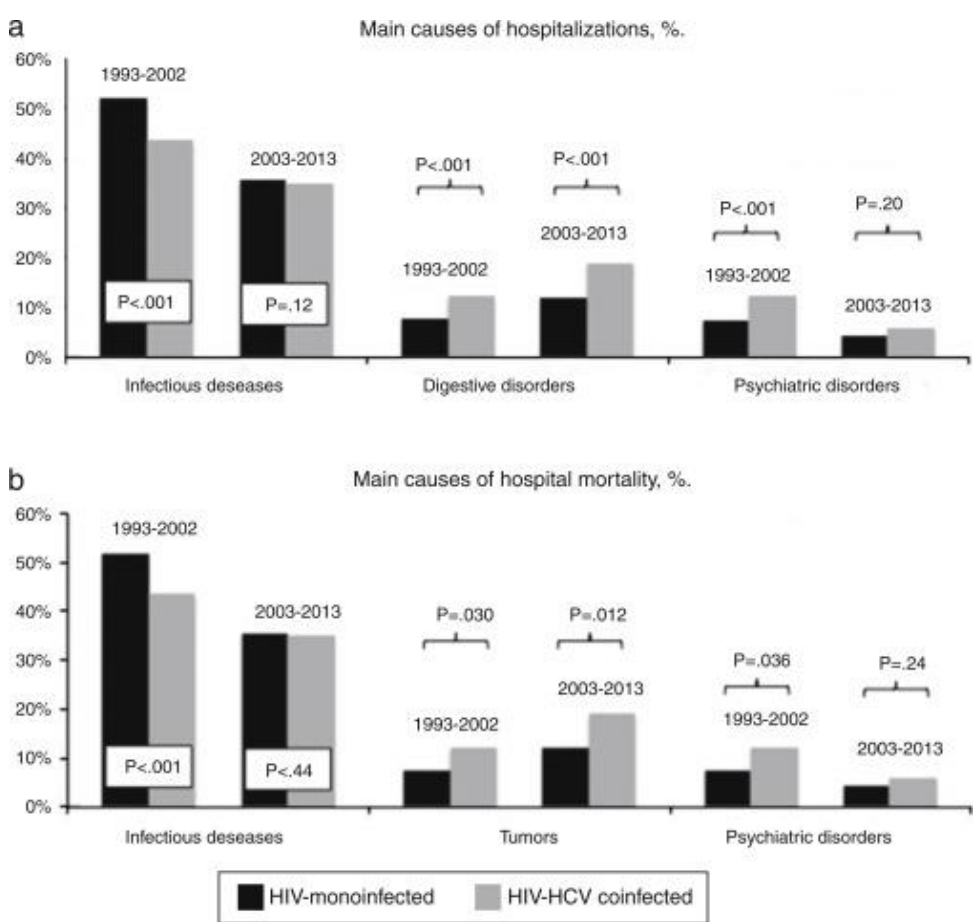

Fig. 3. Main reasons of hospital admission (a) and in-hospital mortality (b) in HIVmono and HIV/HCV-coinfected patients during 1993-2002 and 2003-2013.

Mortality rate of hospitalizations in HIV/HCV coinfected increases from 4.0\% (1993-2002) to $6.2 \%$ (2003-2013), RR = $1.5(1.1-2.1, P<.001)$. There were also differences in mortality reasons: infectious diseases mortality decreased significantly $(\mathrm{RR}=.6$ [.4-.9], $P<.001)$, tumors increased $(\mathrm{RR}=2.1[.5-8.8], P=.01)$ and hepatic decompensations also increased from $15.6 \%$ to $21.2 \%$ (RR: 1.4 [.6-3.3], $P=.005)$ (Fig. 3).

\section{Discussion}

This study evaluates trends in hospitalizations among PLWH in a medical reference area of Northwest Spain. Overall, the hospitalizations rate showed a decline from 31/100 patients in 1993 to $20 / 100$ patients in 2013 , but remains higher than in the general population. These results are concordant with other previously published in different countries and different Health Care Systems. ${ }^{6 ;}{ }^{21}$ The joinpoint analysis established a point of change in 1996. This behavior is related with the introduction of HAART and its rapid impact in AIDS-defining illnesses. In this year, the trend of hospitalization incidence changed from a yearly growing of $11.8 \%$ toward a yearly decreasing of $3.4 \%$.

Changes in the reasons of hospital admission were also observed between the two periods evaluated. Thus, a significant decrease in hospitalizations due to infectious (mainly AIDS-defining diseases) and psychiatric disease or drugs abuse was recognized in contrast to a progressive increase of malignancies specially those non AIDS-defining, chronic respiratory, cardiovascular and liver related diseases. Overall, hospitalizations due to AIDS-defining diseases dropped (from $28.0 \%$ to $16.2 \%$ ) in our cohort, but their mortality did not change significantly (15.0\% in $1993-$ 2003 and $12.3 \%$ in 2004-2013). AIDS-defining diseases and their high mortality remain a current 
problem worldwide; this problem must be addressed from the universalization of HAART and improving the diagnostic strategies. ${ }^{7}$

Accordingly, changes in hospitalization units were also observed. Thus, in the second period there was an increase in hospitalizations in surgical areas and onco-haematologic units, likely due to an increase in the life expectancy among HIV-infected patients in the second period because the access to specific treatments as for the general population. The rates of ICU admissions increased up to 3-times, probably caused by the same reasons.

However, the average length of stay and re-admission rates remain high, similar to those reflected in other studies, ${ }^{10 ; 20}$ probably due to an increase in the comorbidities associated with HIV infection, that involve greater complexity of clinical management in this group of patients.

Despite the improvement in the care of PLWH, the in-hospital mortality remains high; in this cohort the mortality in men is 1.7 times higher than in women, according to data published previously. ${ }^{21 ;} 22$ Non-AIDS deaths increased significantly during the ART era and nowadays are the main cause of in-hospital mortality in PLWH. Non-AIDS infections, cirrhosis and its complications, and malignancies were major contributors to mortality. Non-AIDS mortality increased by $80.5 \%$ between first and second period; consequently, AIDS mortality decreased by $49.0 \%$. Cowell et al., reported similar trends recently, in a huge American cohort. ${ }^{23}$

The 30 days re-admission rate in our cohort was $20.1 \%$, similar to data recently reported by Berry et al. (19.3\%). ${ }^{6}$ The re-admission rate has an important impact on long-term health and mortality rate of PLWH. Indeed, some mathematical models are developed to predict readmission, but they need to be validated in other populations. ${ }^{24}$

Within this cohort, nearly $40 \%$ were $\mathrm{HIV} / \mathrm{HCV}$ coinfected patients. They had more hospitalizations, re-admissions and the sum of the total stays were significantly greater than for HIV mono-infected, similarly to that previously published. ${ }^{16}$ Interestingly, the incidence of hospitalizations in 2013 was double in coinfected compared to HIV mono-infected. Indeed, although the hospitalization rate decreases since 1996, the APC is near to three times higher in mono-infected than in coinfected. Therefore, in terms of hospitalizations and in-hospital mortality, HCV coinfection seems to mask the beneficial effect of HAART and improvements in HIV care, although other factors such IDU or alcohol could also play a significant role. Hospitalizations due to hepatic decompensation are double in the last ten years (2003-2013) compared with the first period (1993-2002). Moreover, Meyers et al. described recently that HCV mortality appears to be relatively stable while total HIV/AIDS deaths are on a decline across the state of Massachusetts in a trend analysis of HIV and HCV using multiple cause of death. ${ }^{25}$ All these data suggest that hospitalizations, decompensations and mortality will increase in the next years if HCV infection is not eradicated. The impact of a wide access to new anti-HCV therapies in HIV-infected patients must be evaluated in the near future. ${ }^{26 ; 27 ; 28}$

There are some limitations in our study that merit discussion. This is a retrospective observational study, using data recorded from a single hospital that it could affect the generalizability of our finding. However, this is a reference hospital with more than 1000-beds and a large cohort of HIV- and HCV-infected patients in follow-up in this institution since the beginning of both epidemics. Although there are not other HIV outpatient clinics in our area, some patients had an admission without any follow up in our clinic; it could overestimate hospitalization rates. Moreover, there are some variables that might be also associated with mortality that were not collected (i.e. smoking, or years under HAART exposure) and therefore its specific impact in hospitalizations and rates of mortality could not be analyzed. Data of CD4 count, HAART and viral suppression were not available, the effect of this important factors in PLWH was not analyzed. Patients admitted in Onco-Hematology Units to receive scheduled chemotherapy (12\%) could overestimate the hospitalization rate in these Units and underestimate the in-hospital mortality in them. The study did not include HCV-infected patients treated with new DAAs based 
therapies, neither a control group of hospitalized HIV-negative patients. Finally, it is possible that the use of the ICD-9 coding system might introduce coding errors, although minority.

In summary, in this large cohort of PLWH, followed during 20 years, a decrease in the hospitalizations rate and a progressive decline of AIDS defining illnesses have been recognized. Consequently, chronic comorbidities and malignancies have been increasing within the last ten years. However, the length of stay, re-admission and the mortality rate remains high. HCV coinfection has a negative impact in these parameters and is associated with increases in the morbidity and mortality and therefore in the resource consumption among PLWH. These findings are essential to improve and optimize the clinical management of PLWH and to pay special attention in those comorbidities that favor the hospitalization and mortality rates nowadays.

\section{Conflicts of interest}

All authors declare no conflicts of interest.

\section{Acknowledgements}

This work was supported in part by grants from Fondo de Investigación Sanitaria (CPII14/00014, PI10/02166, PI13/02266, CM13/00328), and Fundación Profesor Novoa Santos, A Coruña. We would like to thank Biobank of A Coruña (SERGAS) for providing us the technical, ethical and legal advice necessary for the development of our research.

\section{References}

1. A. Mocroft, B. Ledergerber, C. Katlama, O. Kirk, P. Reiss, A. d'Arminio Monforte, et al. Decline in the AIDS and death rates in the EuroSIDA study: an observational study. Lancet, 362 (2003), pp. 22-29.

2. J.E. Sackoff, D.B. Hanna, M.R. Pfeiffer, L.V. Torian. Causes of death among persons with AIDS in the era of highly active antirretroviral therapy: New York City. Ann Intern Med, 145 (2006), pp. 397-406.

3. Antiretroviral Therapy Cohort Collaboration. Causes of death in HIV-1-infected patients treated with antiretroviral therapy, 1996-2006: collaborative analysis of 13 HIV cohort studies. Clin Infect Dis, 50 (2010), pp. 1387-1396.

4. W.E. Cunningham, D.M. Tisnado, H.H. Lui, T.T. Nakazono, D.M. Carlisle. The effect of hospital experience on mortality among patients hospitalized with acquired immunodeficiency syndrome in California. Am J Med, 107 (1999), pp. 137-143.

5. B. Pernas, A. Mena, A. Cañizares, M. Grandal, A. Castro-Iglesias, S. Pértega, et al. Trends on epidemiological, virological, and clinical features among newly diagnosed HIV-1 persons in Northwest Spain over the last 10 years. J Med Virol, 87 (2015), pp. 1319-1326.

6. S.A. Berry, J.A. Fleishman, B.R. Yehia, P.T. Korthuis, A.L. Agwu, R.D. Moore, et al. Thirty-day hospital readmission rate among adults living with HIV. AIDS, 27 (2013), pp. 2059-2068.

7. S.A. Berry, J.A. Fleishman, R.D. Moore, K.A. Gebo, HIV Research Network. Trends in reasons for hospitalization in a multisite united states cohort of persons living with HIV, 2001-2008. J Acquir Immune Defic Syndr, 59 (2012), pp. 368-375.

8. J.H. Kim, G. Psevdos, E. Gonzalez, S. Singh, M.C. Kilayko, V. Sharp. All-cause mortality in hospitalized HIV-infected patients at an acute tertiary care hospital with a comprehensive outpatient HIV care program in New York City in the era of highly active anti retroviral therapy (HAART). Infection, 41 (2013), pp. 545-551.

9. T.A. Crowell, K.A. Gebo, A. Balagopal, J.A. Fleishman, A.L. Agwu, S.A. Berry, et al. Impact of hepatitis coinfection on hospitalization rates and causes in a multicenter cohort of persons living with HIV. J Acquir Immune Defic Syndr, 65 (2014), pp. 429-437.

10. C. López, M. Masiá, S. Padilla, A. Aquilino, C. Bas, F. Gutiérrez. Deaths due to non-AIDS diseases among HIV infected patients: a 14-year study (1998-2011). Enferm Infecc Microbiol Clin, 34 (2016), pp. 222-227.

11. A. Mena, L. Moldes, H. Meijide, A. Cañizares, A. Castro-Iglesias, M. Delgado, et al. Seroprevalence of HCV and HIV infections by year of birth in Spain: impact of US CDC and USPSTF recommendations for HCV and HIV testing. PLOS ONE, 9 (2014), p. e113062. 
12. K.E. Sherman, S.D. Rouster, R.T. Chung, N. Rajicic. Virus prevalence among patients infected with human immunodeficiency virus: a cross-sectional analysis of the US adult AIDS Clinical Trials Group. Clin Infect Dis, 34 (2002), pp. 831-837.

13. N. Brau, R.K. Fox, P. Xiao, K. Marks, Z. Naqvi, L.E. Taylor, et al. Presentation and outcome of hepatocellular carcinoma in HIV-infected patients: a U.S.-Canadian multicenter study. J Hepatol, 47 (2007), pp. 527-537.

14. D. Salmon-Ceron, E. Rosenthal, C. Lewden, V. Bouteloup, T. May, C. Burty, et al. Emerging role of hepatocellular carcinoma among liver-related causes of deaths in HIV infected patients: the French national Mortalite 2005 study. J Hepatol, 50 (2009), pp. 736-745.

15. R. Weber, C.A. Sabin, N. Friis-Moller, P. Reiss, W.M. El-Sadr, O. Kirk, et al. . Liver-related deaths in persons infected with the human immunodeficiency virus: the D:A:D study. Arch Intern Med, 166 (2006), pp. 1632-1641.

16. C. Castellares, P. Barreiro, L. Martin-Carbonero, P. Labarga, M.E. Vispo, R. Casado, et al. Liver cirrhosis in HIV-infected patients: prevalence, aetiology and clinical outcome. J Viral Hepat, 15 (2008), pp. 165172.

17. P. Labarga, J.V. Fernandez-Montero, C. Mendoza, P. Barreiro, V. Soriano. Long-term survival and liver related events after peginterferon/ribavirin therapy in HIV-infected patients with chronic hepatitis $\mathrm{C}$. Antivir Ther, 20 (2015), pp. 65-72.

18. E.J. Aspinall, S.J. Hutchinson, N.Z. Janjua, J. Grebely, A. Yu, M. Alavi, et al. Trends in mortality after diagnosis of hepatitis $\mathrm{C}$ virus infection: an international comparison and implications for monitoring the population impact of treatment. J Hepatol, 62 (2015), pp. 269-277.

19. A. Elixhauser, C. Steiner, L. Palmer. Clinical Classifications Software (CCS), 2008. U.S. Agency for Healthcare Research and Quality (2008).

20. L.M. Wier, M.L. Barrett, C. Steiner, H.J. Jiang. All-cause readmissions by payer and age, 2008. HCUP Statistical Brief \#115 Agency for Healthcare Research and Quality (2012) http://hcupus.ahrq.gov/reports/statbriefs/sb115.pdf.

21. T.A. Crowell, K.A. Gebo, J.N. Blankson, P.T. Korthuis, B.R. Yehia, R.M. Rutstein, et al. Hospitalization rates and reasons among HIV elite controllers and persons with medically controlled HIV infection. J Infect Dis, 211 (2015), pp. 1692-1702.

22. S.M. Ingle, M.T. May, M.J. Gill, M.J. Mugavero, C. Lewden, S. Abgrall, et al. Impact of risk factors for specific causes death in the first and subsequent years of ART among HIV-infected patients. Clin Infect Dis, 59 (2014), pp. 287-297.

23. A. Cowell, S.V. Shenoi, T.C. Kyriakides, G. Friedland, L.A. Barakat. Trends in hospital deaths among human immunodeficiency virus-infected patients during the antirretroviral therapy Era, 1995 to 2011. J Hosp Med, 9 (2015), pp. 608-614.

24. A.E. Nijhawan, C. Clark, R. Kaplan, B. Moore, E.A. Halm, R. Amarasinghang. An electronic medical record-based model to predict 30-day risk of readmission and death among HIV-infected inpatients. J Acquir Immune Defic Syndr, 61 (2012), pp. 349-358.

25. D.J. Meyers, M.E. Hood, T.J. Stopka. HIV and hepatitis C mortality in Massachusetts, 2002-2011: spacial cluster and trend analysis of HIV and HCV using multiple cause of death. PLOS ONE, 9 (2014), p. e114822.

26. G.D. Kirk, S.H. Mehta, J. Astemborski, N. Galai, J. Washington, Y. Higgins, et al.. HIV, age, and the severity of hepatitis C virus - related liver disease. Ann Intern Med, 158 (2013), pp. 658-666.

27. V.L. Re III, M.K. Kallan, J.P. Tate, A.R. Localio, J.K. Lim, M.B. Goetz, et al. . Hepatic decompensation in antiretroviral-treated HIV/hepatitis C-coinfected compared to hepatitis C-monoinfected patients: a cohort study. Ann Intern Med, 160 (2014), pp. 369-379.

28. T.A. Crowell, S.A. Berry, J.A. Fleishman, R.W. LaRue, P.T. Korthuis, A.E. Nijhawan, et al. Impact Hepatitis Coinfection on Healthcare utilization among persons living with HIV. J Acquir Immune Defic Syndr, 68 (2015), pp. 425-431. 